\title{
Quantitative exploration of the barriers and facilitators to nurse-patient communication in Saudia Arabia
}

\author{
Bander S. Albagawi, Linda K. Jones* \\ Discipline of Nursing and Midwifery, School of Health Sciences, RMIT University, Victoria, Australia
}

Received: August 31, 2016

DOI: $10.5430 /$ jha.v6n $1 \mathrm{p} 16$
Accepted: November 30, 2016 Online Published: December 8, 2016

URL: http://dx.doi.org/10.5430/jha.v6n1p16

\begin{abstract}
Nurses with effective communication skills play a critical role in minimising the stress associated with hospitalisation for both patients and their families. Effective communication has become increasingly reported as a key component in effective health care outcomes, which is even more crucial in countries such as Saudi Arabia with a large foreign healthcare workforce. The presence of a large expatriate workforce with a different language from the host society and the ensuing complexity of sociocultural linguistic and heath beliefs systems has been poorly researched. This study aimed to investigate barriers and facilitators of nurse-patient communication in Saudi Arabia using the Nurses' Self-Administered Communication Survey. The survey was distributed to a random sample of 291 nurses working in medical and surgical departments at five hospitals in Saudi Arabia. The results indicate that the Philippine and Saudi Arabian nurses perceived greater barriers to communication with respect to personal/social characteristics, job specifications and environmental factors then nurses of other nationalities. In addition, nurses with shorter experience in Saudi Arabia perceived greater barriers to communication with respect to the clinical situation of patient and environmental factors than the nurses with longer experience. Lastly, nurses who had not attended specialist courses on communication skills acquisition perceived greater barriers to communication with respect to personal characteristics and job specifications than nurses who had attended such courses. This study highlights the need to better prepare expatriate nurses before they enter the workforce in Saudi Arabia on cultural competence and language skills.
\end{abstract}

Key Words: Nurse-patient, Saudi Arabia, Communication, Barriers, Facilitators

\section{INTRODUCTION}

Human communication is a complex process that revolves around exchange of ideas, thoughts and feelings, including both verbal and/or a non-verbal process. ${ }^{[1]}$ Difficulties in communication between the nurse and patient arise due to a complex number of personal, cultural, gendered, professional and organisational management factors. In healthcare, effective communication requires nurses to have key roles such as providing physical care, emotional support and ex- change of information with patients in critical conditions. For instance, in Europe, White ${ }^{[2]}$ studied the interactions between nurses and male patients admitted with chest pain, showing effective care cannot be provided unless nurses are able to communicate effectively with their patients. Similarly, a study examined nurses' difficulties with communication, suggesting that communication is a central aspect of nursing practice. ${ }^{[3]}$ This study indicated that the quality of nursing care is improved through effective communication skills in

\footnotetext{
${ }^{*}$ Correspondence: Linda K. Jones; Email: Linda.jones@ rmit.edu.au; Address: Discipline of Nursing and Midwifery, RMIT University, Victoria, Australia.
} 
the nurse-patient relationship.

Furthermore, nurses need to practice effective communication skills during patient care to inform the competent delivery of biomedical as well as psychosocial information. Constructive communication between nurses and patients influences patients' satisfaction and their adherence to therapeutic regimes, ${ }^{[4]}$ and leads to a reduction of patients' and families' anxiety during hospitalisation. ${ }^{[5]}$ Correspondingly, poor communication may lead to failure to understand the psychosocial and emotional needs ${ }^{[6]}$ and therefore increase distress in patients.

Studies of key communication barriers to providing culturally and linguistically appropriate care found that language and cultural differences remain the greatest impediments to effective communication. Nurses from different cultures to the patients' cultural background may experience communication incongruence that could lead to misdiagnosis, misunderstanding and, above all, the inability of the nurse to articulate the needs of patients, resulting in breakdown of effective patient care. ${ }^{[7]}$

Cultural considerations are essential in any discussion about communication as cultural incompatibility is a major hindrance to effective communication in all human interactions. The nursing profession in Saudi Arabia is a good case in point. Saudi Arabia, and indeed the whole of the Middle East, actively recruited nurses from all over the world in the last few decades, resulting in about two-thirds of the current nursing work force being foreign in origin. ${ }^{[8]}$ The total number of Saudi nurses working at Ministry of Health hospitals in 2007 was 22,590, which represents $44 \%$. In addition, the international nurse workforce was 28,598 , representing $56 \%$ of the total nursing workforce. ${ }^{[9]}$

Language barriers between the expatriate nurses and Saudi Arabia patients are a common concern in Saudi Arabia. Arabic is the predominant language spoken in Saudi Arabia. Unless the expatriate nurses are proficient in Arabic, nursepatient communication becomes a major problem. The problem is compounded by the extensive variation of local dialects that occurs in Saudi Arabian.

Cultural barriers have a negative impact on nursing communication and patient safety and may lead to serious medical errors. This is compounded by the failure of the nurses to understand what doctors are ordering or what someone is asking for, which can have a negative impact on his/her selfbelief, self-worth and work morale. ${ }^{[10]}$ A cultural dichotomy occurs between Arabic speakers and others. In Saudi Arabia, it is a common practice for hospital patients to have family members or close friends (sitters) staying with them. ${ }^{[11]}$
This strong family connection adds another dimension to the nurses' communication skills in that they need to communicate, not only with the patient, but also with the patient's friends, family and sitters. ${ }^{[11]}$ For expatriate nurses from countries where confidentiality of issues relating to a patient is a major concern, this could be a big challenge.

The majority of publications sourced from 2000 related to the experiences of nurse-patient communication are from international clinical settings. Those in a Saudi Arabian context are relatively few. This gap in the knowledge base on the subject of communication skills of nurses in Saudi Arabia and the relevant issues raised by the nurses themselves constituted the reasons for undertaking the research described in this paper.

The aim of this study was to examine the barriers and facilitators of nursing communication towards patients for local Saudi nurses as well as international nurses face within a Saudi Arabian cultural context. An explorative approach was used in order to develop first-time baseline data from which to recommend standardised nurse communication guidelines in order to improve patient safety and resultant healthcare outcomes in Saudi hospitals.

\section{Methods}

This study utilised the Nurses' Self-Administered Communication Survey (NSACS), ${ }^{[12]}$ which was randomly distributed to 291 registered nurses working in surgical and medical departments at five hospitals in Hail district of Saudi Arabia. A probability sampling method was used by randomly generating numbers using the computer in order to be representative of the population. Approval to recruit the participants was obtained from the Higher Research Ethics Committee of the Royal Melbourne Institute of Technology University (Ethics research number BSEHAPP 07 - 11 ALBAGAWI). In addition, the Hail Region Health Affairs Directorate approved special permission prior to commencing the research.

The NSACS survey examined barriers and facilitators of nurses' communication towards patients in Saudi Arabia. The first part of the survey included various demographic details of the nurse. Then the main part of the survey was NSACS which included a section on "personal and social characteristics" focusing on nurse-patient age difference, nurses' religion, nurses' nationality, nurses' unfamiliarity with dialect and unfamiliarity with nursing job description. This was followed by a section on "job specifications", which focused on hard nursing tasks, nursing shift work, patient contact with different nurses and lack of information and skills in communication. The next subscale was on the "clinical situation of patients" and consisted of history of hospitalisation, 
presence of a helper for providing care and patients disease severity. The final subscale was on "environmental factors" which sought information on lack of educational background in communication skills, lack of managerial appreciation from nurses and lack of nurses' and nurses' participation in decision-making. A Likert scale was used for each item requiring a response from 1 to 5 (completely disagree to agree). The approximate time to complete the survey was 15 to 20 minutes. The responses to the NSACS were transferred to the SPSS data editor for the purposes of statistical analysis using the methods described by Field et al. ${ }^{[13]}$

\section{RESUlts}

A total of $\mathrm{N}=267$ nurses provided valid responses to the NSACS, which was a response rate of $91 \%$. The majority of the participants $(\mathrm{n}=192,72 \%)$ were female and most $(n=185,71 \%)$ were between the ages of 18 and 30 . About one-half $(\mathrm{n}=138,53 \%)$ were from Saudi Arabia, while about one-quarter $(\mathrm{n}=72,27 \%)$ were from the Philippines and the remainder were Indian (17\%), South African $(2 \%)$ or other nationalities (7\%). About two-thirds $(\mathrm{n}=178,67 \%)$ had some college education and a relatively low proportion $(\mathrm{n}=70,26 \%)$ were university graduates.

Nearly all of the participants $(n=250,95 \%)$ were employed full-time and more than half $(\mathrm{n}=149,58 \%)$ had worked in Saudi Arabia before. Over half were experienced ( $n=143$, $54 \%$ ), with more than 24 months working at the hospital, the remainder having worked there for one to 24 months. Relatively few $(\mathrm{n}=30,11 \%)$ were very inexperienced, having worked at the hospital for one to four months. Among the 267 participants, the majority $(n=224,84 \%)$ had attended specialist courses, of which the most popular were concerned with patient safety policies $(\mathrm{n}=72,31 \%)$ and communication skills $(n=53,23 \%)$.

The NSACS survey responses for "personal/social characteristics" indicates that in general: (1) there was disagreement that age difference and problems outside work were a barrier to communication (Md [median] = 2 or 3, Mode $=2$ ); (2) the respondents tended towards neutral or agreement about issues concerned with religion, nationality, social class difference, unfamiliarity with job description and aggressiveness of nurses ( $\mathrm{Md}=3$, Mode $=4)$; and (3) the respondents agreed that sex difference, unfamiliarity with dialect and too much expectation of patients were barriers to communication $(\mathrm{Md}=4$, Mode $=4)$. The reliability of the 10 items was adequate (Cronbach's alpha $=0.719)$.

The responses for "job specification" indicate that in general: (1) there was disagreement that lack of interest to work was a barrier to communication $(\mathrm{Md}=3$, Mode $=2)$;
(2) the respondents tended towards neutral or agreement about issues concerned with hard nursing tasks $(\mathrm{Md}=3$, Mode =4); and (3) the respondents agreed that lack of welfare facilities for nurses, low salary, heavy workload, shift work, patient contact with different nurses and lack of information and skills in communication were barriers to communication $(\mathrm{Md}=4$, Mode $=4)$. The reliability of the nine items was good (Cronbach's alpha $=0.781)$.

In relation to "clinical situation of patients" the results indicate that there was general agreement among the nurses that history of hospitalisation, presence of a helper for providing care if the disease/condition is severe and having a contagious disease were barriers to communication $(\mathrm{Md}=4$, Mode $=4)$. The reliability of the four items was adequate (Cronbach's alpha $=0.693$ ).

Finally, for "environmental factors" the results indicate that there was general agreement among the nurses that lack of educational background in communication skills, lack of continuing education in communication skills, lack of welfare and medical facilities for patients, poor sanitation in patients' rooms, feeling of injustice in the workplace, lack of managerial appreciation for nurses and lack of nurses' participation in decision-making, were barriers to communication $(\mathrm{Md}=4$, Mode $=4)$. The reliability of the four items was good (Cronbach's alpha $=0.875)$.

The solution to the factor analysis, copied from SPSS output, is presented in Table 1. This factor analysis condensed the 30 items into four factors, each consisting of subsets of inter-correlated items, reflecting the four sections of the questionnaire. The four factors had eigenvalues $>1.0$. Factor 1 explained $24 \%$ of the variance, Factor 2 explained $11 \%$, Factor 3 explained $7 \%$ and Factor 4 explained 6\%. In combination, the four factors explained $47 \%$ of the variance. The factor loadings were consistently positive and $>0.35$, indicating that all the items contributed substantially to their respective factors and were measured in the same logical direction. There was no need to exclude any of the items because they had negative or negligible loadings.

A factor solution is unlikely to be valid if the constructs reflected by the factors are not realistic. ${ }^{[14]}$ Consequently, the content of the four factors is interpreted. Factor 1 was the most important factor, explaining the highest proportion of the variance. It represented a realistic construct incorporating seven items in Section 4 measuring the barriers to communication related to environmental factors, therefore, called the environmental factors scale. Factor 2, explaining less variance, was a realistic construct incorporated nine items measuring barriers to communication related to job specifications in Section 2 and therefore, called the job specifications 
scale. Factor 3, explaining less variance, was also realistic. It included 10 items that measured barriers to communication related to personal/social characteristics in Section 1, therefore, called the personal/social characteristics scale. Factor 4 explained the least variance and contained the lowest number

Table 1. Factor analysis solution

\begin{tabular}{|c|c|c|c|c|}
\hline & Factor 1 & Factor 2 & Factor 3 & Factor 4 \\
\hline Eigenvalues & 7.2 & 3.2 & 1.9 & 1.7 \\
\hline$\%$ of Variance & 24.2 & 10.6 & 6.5 & 5.6 \\
\hline Cumulative $\%$ & 24.2 & 34.8 & 41.3 & 46.9 \\
\hline \multicolumn{5}{|l|}{ Items } \\
\hline 26. Lack of welfare and medical facilities for patients & 0.748 & & & \\
\hline 25. Lack of continuing education in communication skills & 0.740 & & & \\
\hline 27. Poor sanitation in patients' rooms & 0.738 & & & \\
\hline 29. Lack of managerial appreciation from nurses & 0.729 & & & \\
\hline 24. Lack of educational background in communication skills & 0.675 & & & \\
\hline 30. Lack of nurses' participation in decision-making & 0.671 & & & \\
\hline 28. Feeling of injustice at workplace & 0.662 & & & \\
\hline 14. Heavy nursing workload & & 0.678 & & \\
\hline 13. Hard nursing tasks & & 0.639 & & \\
\hline 17. Nurses' burn-out (physical and mental tiredness) & & 0.635 & & \\
\hline 16. Lack of interest to work & & 0.556 & & \\
\hline 19. Lack of information \& skills in communication & & 0.544 & & \\
\hline 12. Low salary & & 0.508 & & \\
\hline 15. Nursing shift work & & 0.419 & & \\
\hline 11. Lack of welfare facilities for nurses & & 0.414 & & \\
\hline 18. Patient contact with different nurses & & 0.354 & & \\
\hline 3. Nurses religion & & & 0.701 & \\
\hline 6. Social class difference & & & 0.638 & \\
\hline 2. Sex difference & & & 0.605 & \\
\hline 4. Nurses nationality & & & 0.590 & \\
\hline 7. Problems outside work environment & & & 0.549 & \\
\hline 1. Age difference & & & 0.541 & \\
\hline 10. Too much expectation of patients & & & 0.510 & \\
\hline 8. Unfamiliarity with nursing job description & & & 0.495 & \\
\hline 9. Aggressiveness of nurses & & & 0.447 & \\
\hline 5. Unfamiliarity with dialect & & & 0.423 & \\
\hline 22. Disease severity & & & & 0.711 \\
\hline 23. Having a contagious disease & & & & 0.585 \\
\hline 20. History of hospitalisation & & & & 0.417 \\
\hline 21. Presence of a helper for providing care & & & & 0.351 \\
\hline Cronbach's Alpha & 0.875 & 0.781 & 0.719 & 0.693 \\
\hline
\end{tabular}

of items, but it was also realistic. Factor 4 measured barriers to communication related to the clinical situations of patients using four items in Section 3 and it was therefore called the clinical situations of patient's scale.
The four factors each contained closely inter-related items and they were sensible and realistic, reflecting their construct validity and reliability and confirmed the structure of the four sections of the questionnaire. The internal consistency reliability of each of the four factors was indicated by the Cronbach's alpha values ( 0.693 to 0.875 ), which were greater than the threshold of 0.6 conventionally applied to indicate adequate reliability. 
Table 2. Matrix of pearson's correlation coefficients $(R)$ between the four scales

\begin{tabular}{llll}
\hline & Personal/Social Characteristics & Job Specifications & Clinical Situation of Patients \\
\hline Job Specifications & $0.406^{*}$ & & \\
Clinical Situation of Patients & $0.246^{*}$ & $0.386^{*}$ & $0.343^{*}$ \\
Environmental Factors & $0.284^{*}$ & $0.586^{*}$ & \\
\hline
\end{tabular}

* Statistically significant correlation at $\alpha=0.05$

Statistical evidence was obtained using MANOVA to address what is the effect of the nationality of the nurses on a linear combination of the personal/social characteristics scale, the job specifications scale, the clinical situations of patients scale and the environmental factors scale. The theoretical assumptions were not violated. Levine's test indicated that the variances of the dependent variables across the three nationality groups $(\mathrm{n}=138$, Saudi; $\mathrm{n}=72$, Philippines; and $\mathrm{n}=53$, other nationalities) did not deviate from homogeneity at $\alpha=0.01$ with respect to personal/social characteristics $(\mathrm{F}=0.039, p=.961)$, job specifications $(\mathrm{F}=2.894, p=.080)$, clinical situation of patients $(\mathrm{F}=0.336, p=.715)$ and environmental factors $(F=1.974$, $p=.954)$. The covariance matrix also did not deviate from homogeneity at $\alpha=0.01$, indicated by Box's $\mathrm{M}=28.530$, $p=.012$.

The effect of nationality on a linear combination of four dependent variables was found to be statistically significant at $\alpha=0.01$ (Wilk's $\lambda=0.890 ; \mathrm{F}=3.843, p<.001$ ) but the effect size was low $\left(\eta^{2}=0.056\right)$. The differences between the mean scores across the two nationality groups are reflected by the limited extent of the overlaps between the 95\% CIs within the scales in the error bar chart (see Figure 1). The descriptive statistics (see Table 3) and Schefft's pairwise post-hoc tests revealed differences between the mean scores of the nationality groups with respect to three scales. The Philippines nurses $(M=34.03)$ scored higher than the Saudi Arabia nurses $(M=30.78)$ and the other nurses $(M=29.58)$ on the personal/social characteristics scale. The Philippine nurses $(M=32.11)$ and the Saudi Arabia nurses $(M=31.74)$ scored higher than the other nurses $(M=29.17)$ on the job specifications scale. In addition, the Philippine nurses $(M=25.00)$ and the Saudi Arabia nurses $(M=25.17)$ scored higher than the other nurses $(M=22.89)$ on the environmental factors scale. The implications are that Philippine and Saudi Arabia nurses perceived greater barriers to communication with respect to personal/social characteristics, job specifications and environmental factors than the nurses of other nationalities; however, this effect was relatively small, and may have limited practical/clinical significance.

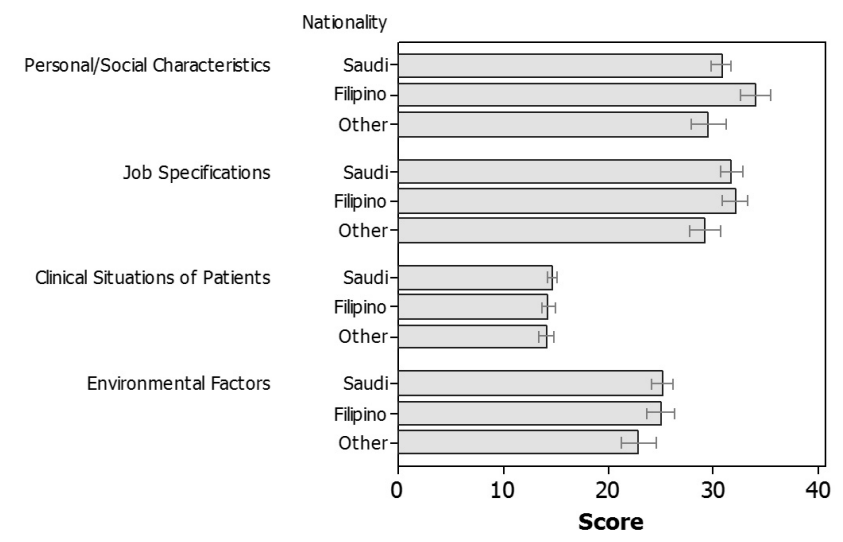

Figure 1. Mean $\pm 95 \%$ CI for the four scales with respect to nationality

Table 3. Mean $\pm S D$ for the four scales with respect to nationality

\begin{tabular}{llllll}
\hline Nationality & & $\begin{array}{l}\text { Personal/Social } \\
\text { Characteristics }\end{array}$ & Job Specifications & $\begin{array}{l}\text { Clinical Situation of } \\
\text { Patients }\end{array}$ & Environmental Factors \\
\hline \multirow{2}{*}{ Saudi } & M & $30.78^{\S}$ & $31.74^{£}$ & $14.65^{£}$ & $25.17^{£}$ \\
& $S D$ & 5.405 & 6.548 & 2.690 & 6.365 \\
\multirow{2}{*}{ Filipino } & M & $34.03^{£}$ & $32.11^{£}$ & $14.28^{£}$ & $25.00^{£}$ \\
& $S D$ & 6.459 & 5.242 & 2.759 & 5.363 \\
\multirow{2}{*}{ Other } & M & 29.58 & $29.17^{\S}$ & $14.13^{£}$ & $22.89^{\S}$ \\
& $S D$ & $5.979^{\S}$ & 5.334 & 2.504 & 6.072 \\
\hline
\end{tabular}

Note. Means scores with different superscripts $\left({ }^{\mathfrak{E}}\right.$ or $\left.{ }^{\S}\right)$ are significantly different

Statistical evidence was obtained using MANOVA to address what effect the time of hospital experience of the nurses had on a linear combination of the personal/social characteris- tics scale, the job specifications scale, the clinical situations of patients scale and the environmental factors scale. The theoretical assumptions were not violated. Levine's test in- 
dicated that the variances of the dependent variables across the three experience groups $(\mathrm{n}=92,<1$ year; $\mathrm{n}=31,1-2$ years; and $\mathrm{n}=143,>2$ years) were homogeneous at $\alpha=0.01$ with respect to personal/social characteristics $(\mathrm{F}=0.904$, $p=.406)$, job specifications $(\mathrm{F}=0.122, p=.885)$, clinical situation of patients $(\mathrm{F}=1.228, p=.295)$ and environmental factors $(\mathrm{F}=4.334, p=.012)$. The covariance matrix was also homogeneous at $\alpha=0.01$, indicated by Box's $\mathrm{M}=29.707$, $p=.094$.

The effect of time of hospital experience on a linear combination of the four dependent variables was statistically significant at $\alpha=0.01$ (Wilk's $\lambda=0.907 ; \mathrm{F}=3.255$, $p=.001)$ but the effect size was very low $\left(\eta^{2}=0.048\right)$. The difference between the mean scores of the three groups is reflected by the limited extent of the overlaps between the 95\% CIs in the error bar chart (see Figure 2). The descriptive statistics (see Table 4) and Schefft's pairwise post-hoc-tests revealed differences between the mean scores of the three groups with respect to two of the scales. On the clinical situation of patient's scale, the nurses with $<1$ year experience $(\mathrm{M}=15.14)$ scored higher than the nurses with 1-2 years of experience $(M=13.32)$ and the nurses with $>2$ years of experience $(\mathrm{M}=14.25)$. On the environmental factors scale, the nurses with $<1$ year experience $(M=25.49)$ scored higher than the nurses with $>2$ years of experience $(M=24.23)$ and the nurses with 1-2 years of experience $(\mathrm{M}=24.52)$. The implications are that nurses with shorter experience perceive greater barriers to communication with respect to the clinical situation of patients and the environmental factors than the nurses with longer experience; however, this effect was relatively small, and may have limited practical/clinical significance.

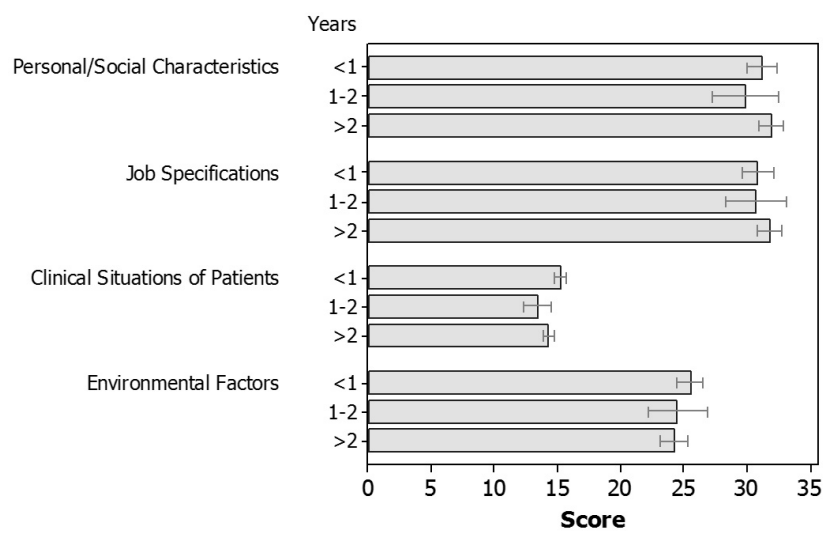

Figure 2. Mean $\pm 95 \%$ CI for the four scales with respect to time of hospital experience

Table 4. Mean $\pm S D$ for the four scales with respect to time of hospital experience

\begin{tabular}{|c|c|c|c|c|c|}
\hline Experience & & $\begin{array}{l}\text { Personal/Social } \\
\text { Characteristics }\end{array}$ & Job Specifications & $\begin{array}{l}\text { Clinical Situation of } \\
\text { Patients }\end{array}$ & Environmental Factors \\
\hline \multirow{2}{*}{$<1$ year } & $\mathrm{M}$ & $31.16^{£}$ & $30.89^{f}$ & $15.14^{\mathfrak{f}}$ & $25.49^{\mathfrak{f}}$ \\
\hline & $S D$ & 5.824 & 6.261 & 2.402 & 4.943 \\
\hline \multirow{2}{*}{$1-2$ years } & M & $29.90^{£}$ & $30.71^{£}$ & $13.32^{\mathfrak{f}}$ & $24.52^{£}$ \\
\hline & $S D$ & 7.203 & 6.599 & 2.948 & 6.521 \\
\hline \multirow{2}{*}{$>2$ years } & M & $31.87^{\mathfrak{f}}$ & 31.77 & $14.25^{£}$ & $24.23^{\mathfrak{f}}$ \\
\hline & $S D$ & 5.824 & 5.791 & 2.663 & 6.612 \\
\hline
\end{tabular}

${ }^{£}$ Means scores with different superscripts are significantly different

Statistical evidence was obtained using MANOVA to address what the effect of the nurses attending specialist courses on a linear combination of the personal/social characteristics scale, the job specifications scale, the clinical situations of patients scale and the environmental factors scale. The theoretical assumptions were not violated. Levine's test indicated that the variances of the dependent variables across the two groups ( $\mathrm{n}=33$, nurses who had not attended specialist courses and $n=234$ nurses who had attended specialist courses) did not deviate from homogeneity at $\lambda=0.01$ with respect to personal/social characteristics $(\mathrm{F}=112, p=.738)$, job specifications $(\mathrm{F}=1.558, p=.213)$, clinical situation of patients $(\mathrm{F}=1.009, p=.316)$ and environmental factors $(\mathrm{F}=0.007, p=.934)$. The covariance matrix also did not deviate from homogeneity at $\lambda=0.01$, indicated by Box's $\mathrm{M}=7.817, p=.682$.

The effect of attending specialist courses on a linear combination of the four dependent variables was found to be statistically significant at $\lambda=0.01$ (Wilk's $\lambda=0.955 ; \mathrm{F}=3.058$, $p=.017)$ but the effect size was very low $\left(\eta^{2}=0.045\right)$. The difference between the mean scores across the two groups is reflected by the limited extent of the overlaps between the 95\% CIs in the error bar chart (see Figure 3). The descriptive statistics (see Table 5) revealed differences between the mean scores of the two groups with respect to two of the scales. On the personal characteristics scale, the nurses who had not attended courses $(M=33.03)$ scored higher than 
the nurses who had $(M=31.18)$. On the job specifications scale, the nurses who had not attended courses $(M=33.21)$ scored higher than the nurses who had $(\mathrm{M}=31.08)$. The implications are that nurses who had not attended specialist courses perceived greater barriers to communication with respect to personal characteristics and job specifications than the nurses who had attended courses; however, this effect was relatively small, and may have limited practical/clinical significance.

\section{Discussion}

The target population for this study was full-time registered nurses assigned to adult medical and surgical departments, including both local nurses and international nurses working at Hail public hospitals in Saudi Arabia. The data indicated that the effect of nurses' nationality was found to be statistically significant according to the NSACS subscale with the Philippine nurses scoring higher than nurses of other nationalities on the personal/social characteristics scale. In other words, the Philippine nurses perceived greater barri- ers to communication with respect to their personal/social characteristics than the nurses of other nationalities. This scale included such items as gender, religion, social class and nurses' nationality.

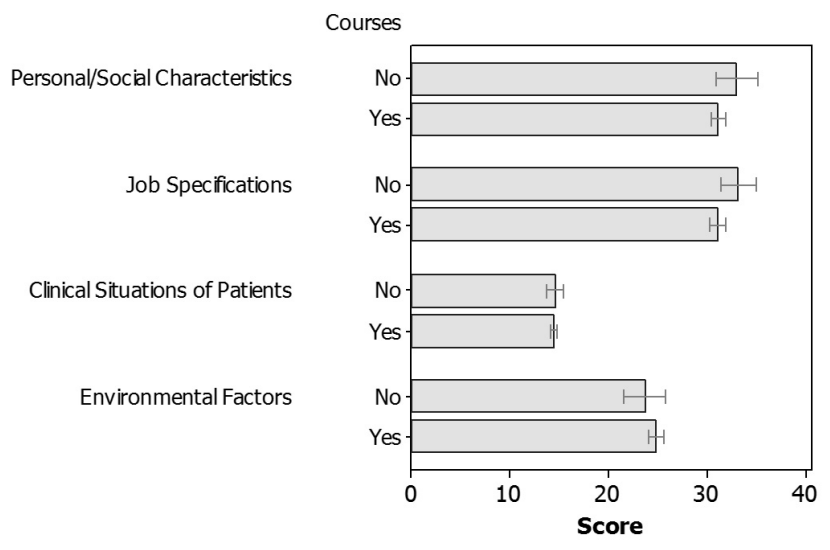

Figure 3. Mean $\pm 95 \%$ CI for the four scales with respect to attending specialist courses

Table 5. Mean $\pm S D$ for the four scales with respect to attending specialist courses

\begin{tabular}{|c|c|c|c|c|c|}
\hline \multicolumn{2}{|c|}{$\begin{array}{l}\text { Attending Specialist } \\
\text { Courses }\end{array}$} & \multirow{2}{*}{$\begin{array}{l}\text { Personal/Social } \\
\text { Characteristics } \\
33.03^{£}\end{array}$} & \multirow{2}{*}{$\begin{array}{l}\text { Job Specifications } \\
33.21^{\mathfrak{f}}\end{array}$} & \multirow{2}{*}{$\begin{array}{l}\text { Clinical Situation of } \\
\text { Patients } \\
14.58^{£}\end{array}$} & \multirow{2}{*}{$\begin{array}{l}\text { Environmental Factors } \\
23.70^{f}\end{array}$} \\
\hline No & $\mathrm{M}$ & & & & \\
\hline No & $S D$ & 6.028 & 5.067 & 2.359 & 5.950 \\
\hline \multirow{2}{*}{ Yes } & M & $31.18^{\S}$ & $31.08^{\S}$ & $14.44^{\mathfrak{E}}$ & $24.85^{\mathfrak{f}}$ \\
\hline & $S D$ & 5.974 & 6.124 & 2.706 & 6.086 \\
\hline
\end{tabular}

Note. Means scores with different superscripts $\left({ }^{\mathfrak{E}}\right.$ or $\left.{ }^{\S}\right)$ are significantly different

Gender and social class differences have been well documented to pose communication barriers between nurses and patient. One study conducted in Iceland indicated the importance of language to personal and professional wellbeing, and how language and culture were common communication barriers. ${ }^{[15]}$ Also, a Middle Eastern-based study presented variations such as age and gender in communication patterns across different clinician groups, healthcare settings and clinical specialties and possible impacts on health outcomes. ${ }^{[16]}$ The same researchers confirmed that the increased feminisation of the medical profession in the Middle East meant that health authorities facing difficulties in the organisation and remuneration of nurses should take into consideration the cultural characteristics of the community.

The differences in religion between Philippine nurses and Saudi Arabia patients would contribute to this increased communication barrier. In England, a study examined the issues specific to Islamic beliefs relevant to healthcare professionals. ${ }^{[17]}$ This study found a fundamental deficit of knowledge of the spiritual beliefs of Islamic people resulted in a cultural-blind approach to patient care. It contended that health professionals should be offered an overview of the tenets of Islamic spiritual beliefs, to enable an understanding of how the Islamic patient's perspective on health and faith are intertwined. Likewise, an Australian study described similar difficulties faced by international nurses in communicating with culturally and linguistically diverse patients in an acute care setting, services and the provision of support for nurses by healthcare workers. ${ }^{[18]}$

Philippine and Saudi Arabia nurses were found to have scored higher than other nurses on the job specification and environmental scales and, therefore, perceived greater barriers to communication in these areas. It is interesting that the nurses from Saudi Arabia scored higher in these areas. Both these scales include mainly organisational and organisation cultural issues which are common issues in any country. For instance, a heavy nursing workload and lack of time were identified as hindering factors to effective communication 
in Iran. ${ }^{[12]}$ Likewise, Kingma ${ }^{[19]}$ identified heavy nursing workload, as well as a lack of welfare facilities for nurses, as being among the most important barriers to nurse-patient communication. Further, Berry ${ }^{[20]}$ expressed that nurses preferred to use a nurse-centred communication style rather than patient-centred approaches when they had time constraints and were pressured to care for a large number of patients.

Another important finding was the significant difference between the participants' years of experience and their communication skills towards patients in a Saudi Arabian context. The implications are that nurses with shorter experience perceived greater barriers to communication with respect to the clinical situation of patients and the environmental NSACS subscales than did the nurses with longer clinical experience. This is not a surprising finding as more experience results in more "on the job training" in communication and thereby reduce the barriers. In the literature, factors that were recognised to increase the effectiveness of communication with patients were in fact the nurses' prior training and experience working with people from different countries. ${ }^{[21]}$

Additional findings in the current study included the effect of nurses attending specialist communication courses. The implications being that nurses who had not attended specialist courses perceived greater barriers to communication with respect to personal characteristics and job specifications NSACS subscales than the nurses who had attended courses. In Saudi Arabia, most international nurses receive little formal education to assist them prior to their arrival. ${ }^{[8]}$ Providing nurses with education on how to prevent communication breakdown with patients has been documented to be of crucial importance. ${ }^{[22]}$

The communication issues are clearly more prominent in populations of large expatriate health workforces in countries like Saudi Arabia and the UAE than in mono-cultural workforces. The presence of a large expatriate population with a different language from the host society results in multiple languages as well as cultural differences in a healthcare setting. These differences exist in nursing staff dialects as well as in the multiple dialects of the patients. In the presence of such linguistic and cultural differences, local language speaking nurses also report barriers to communication when the patients belong to different dialectical language and ethnic group. For example, El-Amouri and O'Neill ${ }^{[22]}$ reported on cultural influences in the diverse nursing population in the UAE, which was 28\% Arabic, $63 \%$ Asian and 2\% other nationalities. ${ }^{[22]}$ Similar to the current study findings, the same authors indicated that the hospitals in the UAE were facing professional and managerial concerns due to wide ranging linguistic and sociocultural backgrounds.
The current study's findings indicated that there was significant need for education in communication skills. Similarly, in South Africa, researchers interviewing international nurses on their work experiences in Saudi Arabian hospitals found they faced stress when completing the mandatory core competencies, courses and workshops. ${ }^{[23]}$ This points to the need for better preparation of these nurses prior to working in Saudi Arabia.

Limitations are that this study only focused on nurses' perspective and did not ask patients about barriers and facilitators to communication. There was no attempt made to control acquiescent response bias, which is the tendency of many respondents to agree or strongly agree to most questionnaire items, irrespective of whether or not they actually do agree to them in reality. There is a need for a qualitative study in this area to be able to identify more specifics regarding the barriers and facilitators.

The findings from this study offer a comprehensive understanding of the cultural values, work experience and benefits of professional education in communication for both Saudi Arabia and international nurses employed in Saudi Arabian hospitals.

\section{Conclusions}

Communication is essential in order to provide high quality healthcare, promote patient satisfaction and patient adherence with treatment. Nurses should, therefore, understand perception differences between patients and nurses, and practice strategies to reduce the associated communication barriers. This study contributes to promoting awareness, and the importance of, recognising the barriers and facilitators of nurse-patient communication in multicultural diversity in order to provide improved healthcare outcomes for patients in the Hail region of Saudi Arabia. Also, this project indicated the need for effective orientation and ongoing educational packages on communication skills for newly employed Saudi Arabia and expatriate nurses. This research has provided significant and new knowledge in the area of barriers to effective communication skills in Middle Eastern healthcare settings, and can be used to facilitate communication and improve patient care outcomes in multicultural contexts.

\section{ACKNOWLEDGements}

This work is part of Doctoral study undertaken through the Royal Melbourne Institute of Technology (RMIT) University. A note of appreciation goes to the participants for their time. Thanks also to Professor Eleanor Holroyd for supporting this research.

\section{CONFlicts of InTEREST Disclosure}

The authors declare they have no conflicts of interest. 


\section{REFERENCES}

[1] Heater ML. Ethnocultural considerations in family therapy. Journal of the American Psychiatric Nurses Association. 2003; 9(2): 46-54. https://doi.org/10.1016/S1078-3903(03)00020-X

[2] White AK. Interactions between nurses and men admitted with chest pain. European Journal of Cardiovascular Nursing. 2003; 2(1): 47-55. https ://doi.org/10.1016/S1474-5151(02)00090-7

[3] Sheldon LK, Barrett R, Ellington L. Difficult communication in nursing. Journal of Nursing Scholarship. 2006; 38(2): 141-147. PMid: 16773917. https://doi.org/10.1111/j.1547-5069.2006.0 $0091 . \mathrm{x}$

[4] Gilbert DA, Hayes E. Communication and outcomes of visits between older patients and nurse practitioners. Nursing Research. 2009; 58(4): 283. PMid: 19609180. https://doi.org/10.1097/NNR Ob013e3181ac1413

[5] Back AL, Arnold RM, Baile WF, et al. Approaching difficult communication tasks in oncology. CA: A Cancer Journal for Clinicians. 2005; 55(3): 164-177.https://doi.org/10.3322/canjclin.5 5.3 .164

[6] Reynolds WJ, Scott B. Do nurses and other professional helpers normally display much empathy? Journal of Advanced Nursing. 2000; 31(1): 226-234. https ://doi.org/10.1046/j.1365-2648. 20 $00.01242 . x$

[7] Hammoud MM, Siblani MK. Care of Arab Americans and American Muslims. In J. Bigby (Ed.), Cross-cultural medicine. Philadelphia: American College of Physicians; 2003. 161-194 p.

[8] Halligan P. Caring for patients of Islamic denomination: Critical care nurses' experiences in Saudi Arabia. Journal of Clinical Nursing. 2006; 15(12): 1565-1573. PMid: 17118079. https : //doi.org/10.1111/j.1365-2702.2005.01525.x

[9] Ministry of Health. Health statistical year book 2009. Riyadh: Ministry of Health of Saudi Arabia; 2009.

[10] Fluehr-Lobban C. Islamic societies in practice. University Press of Florida. 2004.

[11] Bosma H, Apland L, Kazanjian A. Cultural conceptualization of hospice palliative care: A literature synthesis final report. 2008.

[12] Anoosheh M, Zarkhah S, Faghihzadeh S, et al. Nurse-patient communication barriers in Iranian nursing. International Nursing Review. 2009; 56: 243-249. PMid: 19646175. https ://doi.org/10.111 $1 / j .1466-7657.2008 .00697 . x$
[13] Field A. Discovering statistics using SPSS. Thousand Oaks: Sage; 2009.

[14] Hair JF, Anderson RE, Babin BJ, et al. Multivariate data analysis. Upper Saddle River, NJ: Prentice Hall; 2010.

[15] Magnusdottir H. Overcoming strangeness and communication barriers: A phenomenological study of becoming a foreign nurse. International Nursing Review. 2005; 52(4): 263-269. PMid: 16238722. https://doi.org/10.1111/j.1466-7657.2005.00421.x

[16] Sandhu H, Adams A, Singleton L, et al. The impact of gender dyads on doctor-patient communication: A systematic review. Patient Education and Counseling. 2009; 76(3): 348-355. PMid: 19647969. https://doi.org/10.1016/j.pec.2009.07.010

[17] Rassool GH. The crescent and Islam: Healing, nursing and the spiritual dimension. Some considerations towards an understanding of the Islamic perspectives on caring. Journal of Advanced Nursing. 2000; 32(6): 1476-1484. https://doi.org/10.1046/j.1365-2648. $2000.01614 . x$

[18] Cioffi J. Communicating with culturally and linguistically diverse patients in an acute care setting: Nurses' experiences. International Journal of Nursing Studies. 2003; 40(3): 299-306. https : //doi.org/10.1016/S0020-7489(02)00089-5

[19] Kingma M. Nurses on the move: A global overview. Health Services Research. 2007; 42(3): 1281-1298. PMid: 17489915. https : //doi.org/10.1111/j.1475-6773.2007.00711.x

[20] Berry JA. Nurse practitioner/patient communication styles in clinical practice. Journal for Nurse Practitioners. 2009; 5(7): 508-515. https://doi.org/10.1016/j.nurpra.2009.02.019

[21] Hemsley B, Sigafoos J, Balandin S, et al. Nursing the patient with severe communication impairment. Journal of Advanced Nursing. 2001; 35(6): 827-835. PMid: 11555030. https ://doi.org/10.1 046/j.1365-2648.2001.01920.x

[22] El-Amouri S, O'Neill S. Supporting cross-cultural communication and culturally competent care in the linguistically and culturally diverse hospital settings of UAE. Contemporary Nurse. 2011; 39(2): 240-255. PMid: 22551436. https ://doi.org/10.5172/conu. 2 011.39 .2 .240

[23] van Rooyen D, Telford-Smith CD, Strumpher J. Nursing in Saudi Arabia: Reflections on the experiences of South African nurses. Health SA Gesondheid. 2010; 15(1): 1-9. 